\title{
Power users in online democracy: their origins and impact
}

Jonathan Bright (corresponding author), Oxford Internet Institute, University of Oxford, $1 \mathrm{St}$ Giles Oxford, Oxford OX1 3JS, UK. jonathan.bright@oii.ox.ac.uk

Sandra Bermudez, Political Science Department, Universidad Nacional de Educación a Distancia, C/ del Obispo Trejo, 2, 28040 Madrid (Spain)

Jean-Benoit Pilet, Université Libre de Bruxelles, Campus du Solbosch, CP124, avenue F.D. Roosevelt 50, 1050, Bruxelles, Belgium.

Thomas Soubiran, Université de Lille, 42 Rue Paul Duez, 59000 Lille, France.

\section{Abstract}

One well-known characteristic of participatory websites is that the distribution of contribution levels is highly skewed: most people who make use of the service contribute only a little, but a small minority, often known as 'power users', contribute a lot. These power users are understudied in the literature on online democratic participation: this article aims to fill this gap. Based on a unique observational dataset of hundreds of thousands of users of an electronic petitioning platform, we show that having more free time is an important determinant of becoming a power user, as is having a positive initial experience with the site. We also show that power users are both more effective than regular users and that their interests differ substantially from 'normal' users: meaning that these small groups have a powerful (and distorting) influence on overall outcomes for the site.

\section{Introduction}

Over the last two decades the internet has been the source of a wide variety of democratic innovations, from the creation and maintenance of political forums and discussion sites to the 
establishment of e-petitioning platforms, voting advice applications, and social media enabled activist organisations and campaigns. While initially niche parts of the democratic landscape, the rapid adoption of these tools (especially social media) by political elites has meant that today large parts of political life, in the form of opinion formation, news and information dissemination, discussion and even participation, are now played out online (see e.g. Bright, 2016; Yasseri \& Bright, 2016; Margetts et al., 2015; Kaye \& Johnson, 2002; Utych \& Kam, 2014; DiGrazia et al. 2013).

One well established characteristic of participatory websites, including those focused on edemocracy, is that contribution levels typically exhibit a highly skewed distribution, whereby the majority of people who make use of the service contribute only a little, whilst a small minority contribute a lot (Nielsen, 2006). In many cases this active minority, who are often described as "power users", account for a significant percentage of all the activity taking place: they create most of the discussion threads, write most of the comments, upload most of the reviews, sign most of the petitions and so on. For example, the petitioning platform change.org claims a user base of more than 230 million users ${ }^{1}$. However research on the site revealed that $50 \%$ of the signatures to petitions were made by just $5 \%$ of this user group (Huang et al., 2015). And change.org is by no means unusual: online chat forums (Fisher et al., 2006; Whittaker et al., 1988), social networking sites (Brandtzaeg \& Heim, 2011), Wikipedia (Panciera et al., 2009), crowd science platforms (Sauermann \& Franzoni, 2015) and educational platforms (Cobo et al., 2016) have all been shown to contain skewed participation dynamics, with Nielsen going so far

\footnotetext{
${ }^{1}$ Figure retrieved on 24/7/2018 from https://www.change.org/
} 
as to claim they have "existed in every online community and multi-user service that has ever been studied" (Nielsen, 2006).

The existence of power users is potentially of considerable significance in the study of electronic democracy. Studies of online forums have also often portrayed those who put in the effort to participate as power users in a positive light, as members answering a "higher calling" (Preece \& Shneiderman, 2009, p. 24) to get things started before others join in (Kittur et al., 2007). They are contrasted to free riding "drive by participants" (Boldi et al., 2011) or "lurkers" (Edelmann, 2013; Sun et al., 2014) who benefit from the collective action but do little or nothing to get involved. However unequal participation is also widely acknowledged as a normative problem for democracy, as it translates into unequal political influence for the groups which participate the most (Gallego, 2007; Lijphart, 1997). By participating more in online democratic activities, power users give themselves more "voice" than a general user, something which potentially allows them to focus the activities of the community on their own particular interests. Power users have also been criticised for becoming possessive and territorial about the communities they contribute so much to, something which might actively put off new users (Brandtzæg \& Heim, 2008).

Despite their apparent importance, and the frequency with which they have been observed, literature in online democracy has thus far placed little focus on power users. Hence we know little about why they emerge. Furthermore, apart from the obvious fact that they contribute a lot, we do not know much about their direct impact. This article seeks to remedy this deficit, by answering two major questions. First, we seek to explore factors explaining why some users become power users and others do not, focusing in particular on both their personal characteristics (especially the amount of free time they have) and their initial experiences of 
interacting with the site. Second, we explore the impact of power users on their community, in terms of both what they are interested in creating and how successful these creations are.

The article is structured in the following way. In the next section, we review theory surrounding power users, generating expectations about both the reasons for their emergence and the potential impact they might have. Then, we describe our methods, and outline our dataset which is drawn from observational data on a major electronic petitioning platform. Finally, we outline our results, showing that initial positive experiences with a site make a difference to generating power users, as does increasing levels of free time. We also show that power users typically have more successful engagements with the site, and that their interests differ substantially from the community at large. We conclude by discussing the consequences of our findings for theories of electronic democracy.

\section{Theorising Power Users}

We will begin our theoretical section by looking at existing work explaining the emergence of power users, with a particular focus on online democratic communities. One core line of thinking places the focus on how differences in pre-existing resources make some people inherently more likely to become power users than others. There is of course a widespread pre-existing literature on the importance of resource inequalities in political participation in general (Nie \& Verba, 1975; Brady et al., 1995; Gallego, 2007; Parry, 1992; Vaccari, 2013; Kittilson, 2005). In terms of voting behaviour, education and wealth are the most commonly highlighted resources of importance: participating politically often requires certain skills and knowledge (making education important); it can also require financial resources (for example, purchasing access to 
political information). Research has shown that these resources also matter when explaining online participation (Schlozman et al., 2010), something which can theoretically be explained by the fact that use of the internet is something that also requires both skills and financial resources. The limited amount of empirical work there is on power users has offered support for the idea that resources make a difference, on the basis that behavioural differences between power users and normal users are often apparent from early interactions with the website (Pal et al., 2011; Panciera et al., 2009; Panciera et al., 2010).

However, becoming a power user is conceptually quite distinct from sporadic electoral participation. Rather, power users are more similar to those who engage in "high commitment" political activities such as going on marches, joining political parties and attending rallies. For these activities, wealth and education have been found to make little impact (Brady et al., 1995). Rather, availability of free time has frequently been highlighted as a resource which enables this type of activity (see e.g. Wilson, 2000). Indeed, Brady et al. have shown that having a lot of free time makes more difference to participating in high commitment political acts than attributes such as having a high family income. These types of activities require a considerable amount of free time to be achieved, and are hence much more likely to be undertaken by those with higher levels of free time, such as the retired or the unemployed. This might also be the case for power users: in order to participate a lot, they might need to dedicate considerable time to the activity in question.

One could question whether time is actually crucial as a resource when it comes to online democracy. Compared to other forms of mobilization, like street demonstration or political activism, online activities are relatively cost-free in terms of time (Margetts et al., 2015). For example, signing an e-petition only takes a few seconds and a few clicks. Furthermore, the more 
contributions a user makes, the less time each one will take (for example, the time cost of creating an account will only apply to the first transaction). However, it may also be important to separate out the time required to physically perform the transaction (which is much lower online) and the time required to learn about an issue, form a view on it and decide to take action (which is arguably constant between offline and online participation). Hence there are also good reasons to think that time continues to be important in the context of online democracy. These remarks on time constraints lead us to propose the following first hypothesis about the emergence of power users:

\section{H1.1: Those with more free time are more likely to become power users}

A second line of thinking emphasises the importance of experiences in encouraging users to become active participants. Individuals who are power users in one context may play a much more minor role in another website (Muller, 2012): hence resources such as free time cannot explain everything. Of particular significance in this respect is Preece and Shneiderman's readerto-leader framework (Preece \& Shneiderman, 2009), which builds on the theory of "legitimate peripheral participation" (Lave \& Wenger, 1991). This framework suggests that new users of an online community start off by doing simple things, and then either progressively become more involved or (more commonly) decide to drop out entirely. While they feel it inevitable that most casual users of a website cannot be converted into regular ones, Preece and Shneiderman highlight that the results of early interactions can shape decisions to participate more. Such results could include successes with using the interface or feedback from the site itself. For example, rating systems which recognise the quality of contributions are known to increase their frequency (Preece \& Shneiderman, 2009, p. 19). These 'results' could also concern direct interactions with other users on the site. Evidence from online discussion boards has shown 
support for this idea, with "satisfying discussions" known to increase collaboration (Schroer \& Hertel, 2009) whilst getting a reply to a question also increases the probability of posting again (Arguello et al., 2006). They could also concern measures of how positively other users of a community perceive their contribution: for example, the number of reactions a post receives on a social media platform, or the number of signatures achieved by a petition.

Literature on democracy lends support to this view through research on the idea of political efficacy (that is, people's perceptions of whether their actions are likely to make a difference). Research has shown that people's perceptions of the likelihood of success have an impact on the likelihood of participation (Goodin \& Dryzek, 1980). These perceptions of efficacy can be shaped by life experiences (for example, unemployment is known to cause feelings of lower political efficacy: see e.g. Scott \& Acock, 1979); but they can also be formed by previous participative interactions (Finkel \& Muller, 1998), as well as real-time information about the number of other people participating in a particular activity (Hale et al., 2014).

However, it is also possible that perceptions of efficacy and success have less impact for power users than they do for other users. For example, Margetts et al. have shown that people who are willing to initiate collective actions differ from those willing to join in later in terms of their psychological profile (Margetts et al., 2015). They highlight in particular that these initiators have psychological characteristics which lead them to have a lower "threshold" for participation, borrowing the terminology of Granovetter (1978), who defined an individual's participation threshold as the number of other people who have to participate in a collective activity before that person decides to join. If power users are also those with low thresholds, then they may place less importance on actual outcomes, and be more willing to take part regardless of apparent chances of success. This idea receives support in a study by Huang et al. on online petitioning 
(Huang et al., 2015), who found that highly active users were willing to sign petitions with little chance of success.

These conflicting potential impacts of successful interaction with a website lead us to pose our second hypothesis about the emergence of power users:

H1.2: People who had successful initial interactions with the website are more likely to develop into power users

We will now move on to considering theory relating to the impact of power users on the community with which they are engaging. Two key debates can be found in this area. The first concerns whether the interests of power users diverge in important ways from the interests of normal users in such a way that, through their heavy engagement activities, they distort the focus of the community, leading it to focus on issues which are not of general interest (Oser et al., 2014), something which may exacerbate participation inequality. A range of literature provides theoretical support for this idea. As discussed, power users are likely to have lower participation thresholds, and hence be willing to get involved in activities which have little chance of success (Huang et al., 2015; Margetts et al., 2015). This may allow them to participate in a wider range of topics, many of which may be of niche interest. Morozov has referred to this type of person as a "promiscuous clicktivist", who satisfies an urge to participate in the democratic process by participating in a "mad shopping binge" in online democratic forums, simply clicking on anything that has the slightest appeal (Morozov, 2011, p. 190). In broader democratic theory, this type of impact might be considered similar to that of the "floating voters" of post-war democracy, who voted with little forethought or clear interest in politics, but who nevertheless were crucial for deciding the overall result (Benewick et al., 1969). 
May's "curvilinear" theory of political party membership provides a contrasting reason to suggest power user and normal user interests might diverge. May suggests that party members will be more radical than either elected politicians or the average voter (May, 1972). The theory, for which there is considerable supporting evidence (though not all studies have agreed with it see e.g. Kitschelt, 1989; Norris, 1995), revolves around the incentives for participation in parties. The costs of participation in terms of time are very high: hence the pay-off must be equally high. However, the pay-offs available to politicians (such as the chance of holding office or helping constituents) are unavailable to party members: May argues that that radical ideological principles are the only satisfactory way of explaining party membership. Hence, party members exist to drive a policy agenda which they would otherwise find too moderate. In the case of power users, these 'radical' principles might relate not only to the intensity of viewpoints, but the actual topic of issues being covered: they may feel that the community as a whole is not focusing enough on their topics of interest. Empirical support for this idea has been found in work by Puschmann, Bastos \& Schmidt (2017). These lines of thinking lead us to develop our first impact hypothesis:

\section{H2.1: Power users will have substantially different interests to normal users}

The second facet of impact concerns whether power users wield disproportionate influence not only through their increased activity, but also in terms of the amount of engagement generated by their activities: for example, by creating petitions which receive more signatures than average, creating discussion threads which receive lots of replies, or creating online social movements which receive more members, etc. (Priedhorsky et al., 2007). This increased 'successfulness' may emerge because, over a long history of interaction with a site, they may come to learn why some things are well received by a community whilst others aren't, and thus become more adept 
at starting successful initiatives. Power users have often been regarded as "starters" or "leaders" of online democratic movements and associations, getting things going before other more general users arrive (Karpf, 2011; Margetts et al., 2015; Preece \& Shneiderman, 2009). As Kittur et al. put it when studying Wikipedia: "like the first pioneers or the founders of a startup company, the elite few who drove the early growth of Wikipedia generated enough utility for it to take off as a more commons-oriented production model; without them, it is unlikely that Wikipedia would have succeeded" (Kittur et al., 2007, p. 8). In addition to starting things, power users may also be crucial in keeping the community going, by replying quickly to new users, moderating and shaping the contributions of others (Lampe \& Resnick, 2004), or offering them some other form of successful interaction (Arguello et al., 2006). It is for these reasons, of course, that much literature in social computing has focussed on the issue of how to retain power users in a website, and even increase their number (Pal et al., 2011; Preece \& Shneiderman, 2009). This line of thinking leads us to the development of our second impact hypothesis:

H2.2: Power users will be more successful than regular users in their interactions with participatory websites

\section{Data and Methods}

The empirical section of our study is based on the French language electronic petitioning website lapetition.be, which is the most widely used e-petition website in Belgium and France, and which also hosts petitions from a variety of other Francophone countries such as Canada and Switzerland. An electronic petitioning website is a useful case on which to test our hypotheses for several reasons. Signing a petition has always been one of the most frequently conducted types of democratic participation (Cruickshank \& Smith, 2011; Contamin, 2012), with the use of 
e-petitions having spread to most Western democracies (Lindner \& Riehm, 2009). The large user bases for electronic petition websites hence facilitate the discovery of power users. E-petitioning is also a broad activity: petitions can be created on any topic of interest. This allows us to assess the extent to which different types of users are interested in different types of topic. However, of course it is worth noting that restricting ourselves to one type of online democratic activity is also a limitation: it may be that our findings cannot be generalised beyond the case of petitioning itself. For example, other online democratic activities (such as engaging in political discussion) may require substantially different skill sets or levels of time commitment.

The group hosting the website lapetition.be provided data for the study in the form of anonymised user information which covered the timespan from 2006 to 2015 . In total, over 15,000 e-petitions were created on the website in this period, whilst almost 4 million signatures were registered by nearly 2 million users. For the analyses in this paper, we decided to focus solely on users based in France, which left us with a subset of almost 850,000 users. Initial descriptive statistics on the activity levels of this set of users are provided in table one. The distribution of activity on the site follows the same highly skewed distribution observed in other websites. At one end of the spectrum, around $78 \%$ of users of the site signed just one petition. This group of users is important in absolute terms: they account for almost $40 \%$ of the overall signatures made on the site. Yet we can also see that they punch below their weight to a considerable degree in terms of the amount of "voice" they have, if we consider voice to be equivalent to the number of petitions signed. At the other end of the spectrum, $0.1 \%$ of users signed more than 100 petitions: in total, this small group contributed $6.3 \%$ of the total signatures on the site. The "voice" of a member of this group hence far outweighs the voice of a member of the one signature group. We chose to treat this group of individuals which signed more than 100 
petitions as "power users" for the purposes of this study. This is an arbitrary cutoff, although it reflects the fact that we want to study the upper reaches of the distribution (these people are above the $99.9^{\text {th }}$ percentile in terms of activity levels).

[table one about here]

We will now describe how we code the independent variables relevant to the study. We divide up the description according to the hypothesis that is being tested.

\section{H1.1: Free-time}

To determine the amount of time an individual user has available, we make use of information about their employment status. Employment is a useful proxy for free time which is often referred to in the literature on resource theory (see e.g. Schlozman, Burns \& Verba, 1999, p.42) : those without a job should, all else equal, have more free time than those with a job. When signing a petition, individuals are asked what their profession is. The information entered in response is "free text": i.e. individuals can respond however they want, rather than selecting from a list of options. This resulted in a list of hundreds of thousands of different answers. We selected all professions which appeared at least 1,000 times in this list (i.e. at least 1,000 people listed them as a response). Two authors of the paper then coded each of these professions into one of four categories: employed; unemployed; retired, or "other"' Categorising the data in this way allows us to compare a large selection of people with a job to those who, through either retirement or unemployment, do not have one. The authors performing the coding had a $98 \%$

\footnotetext{
2 The two main types of profession in the "other" category were student and homemaker. It is, we believe, ambiguous whether these groups have more or less free time than people with a job, hence we decided to exclude them from the analysis.
} 
agreement rate, which gave a Krippendorff's alpha of 0.94 . In total, approximately 200,000 individuals were coded as being either employed, unemployed or retired, or around $25 \%$ of our total user base.

\section{H1.2: Interactions}

Our second hypothesis states that people with successful initial interactions with a website will be more likely to develop into power users. To assess this, we simply measured the final number of signatures achieved by the first petition a user signed. We assume that the more signatures this petition gains, the greater the signal a user receives about the success of the collective activity in which they just participated, and hence the potential efficacy of their actions in terms of signing more petitions. However, as we described above, the fact that power users may also have lower participation thresholds may confound the effect of this variable: as power users may be more willing to sign petitions which have a low number of signatures at the time. Such petitions are, clearly, less likely to be successful. Hence we also include as a further variable a measure of the average number of signatures which had already been made on each petition that a given user signed. This allows us, in a way, to specify a user's "threshold": the amount of signatures they typically like to see on another petition before they also sign it. Including this variable as a covariate allows us to measure the impact of the final outcome of a petition independent of the fact that some people are likely to select petitions which have higher or lower initial numbers of signatures.

\section{H2.1: Topic}

Our first impact hypothesis specified that power users ought to have significantly different interests to normal users. In the context of a petitioning website, interests can be defined as the 
topic of petitions which are either signed or created by a given user. The topic of a petition is a piece of data which also came from the website: when creating petitions, users themselves are asked to assign them into one of a limited number of topic categories, which were: "Animal Protection”, “Art and Culture”, “Environment”, "Human Rights”, “Humour”, “Leisure”, "Politics", "Others" and "Social Issues".

\section{H2.2: Success}

Our second impact hypothesis specified that power users were more likely to have successful interactions with an online community than normal users. In the context of our petitions website, we measure this by looking at the outcomes of petitions created by users. The success of a petition was defined as the final number of signatures it receives.

\section{Control variables}

We also include two control variables in the study. First, we assigned individuals in the dataset to small administrative areas in France, known as communes. Assignment was performed on the basis of geographic data which users themselves provided to the website (in particular, their country and town of origin, and in some cases their postcode). Overall it was possible to assign $92 \%$ of users to a commune. This assignment allowed us to run multi-level models, with the aim of controlling for any regional level effects in the frequency of petitioning (for example, it might be that those living in densely populated urban areas see more petitions which affect them directly, and are hence more likely to join in). Second, we also decided include the date when users first started using the website as a general control variable: people who have been using it since its inception are, naturally, much more likely to have signed more petitions than people who have only just discovered it. 


\section{Analysis}

We will begin the analysis by seeking to explain the emergence of power users on the lapetition.be website. As we described in the theoretical section, we have two main hypotheses to test: first, that this is a result of resource effects, with people with more free time more likely to participate (H1.1); second, that it is a result of experiences, with successful initial interactions likely to promote further levels of signatures (H1.2).

We address these questions in table two, which contains two types of regression models. Model A1 is a multilevel Poisson regression. This model allows us to look at which variables are, on average, correlated with increasing numbers of signatures on the platform. We make use of a multilevel model to control for unobserved geographic effects in the data. We use a Poisson distribution because this is appropriate for the count data that we have in our dataset.

[table two about here]

The Poisson model serves as a basis of comparison: the effects reported within them are average ones, which will furthermore be biased towards the small end of the scale, which is where the majority of the data is (as shown in table one). However, our interest is not only in these average tendencies, but also in the factors which distinguish the small group of highly active power users from the majority of less active ones. Hence we also produce a series of logistic regression models (B1-B4). Each model compares the chance of becoming a power user (i.e. signing more than 100 petitions) with the chance of falling in one of the other categories of users identified in table one (so, for example, model B1 assesses the likelihood of a user falling in either the one signature group or the 100+ group, with all other users discarded). These models offer a convenient way of identifying statistically significant differences between power users and 
groups of users with other contribution levels. All coefficients are exponentiated, and hence can be interpreted as incidence ratios for the Poisson regressions and odds ratios for the logistic regressions. All numerical variables are standardized, and several of them were log transformed to better approximate normality - these transformations are noted in the table.

The Poisson regression (model A1) offers support for both of our hypotheses. Free time makes a difference: not having a job leads to more signatures (H1.1). In terms of experiential factors, meanwhile (H1.2), there is good evidence that the result of the first petition someone signs matters: the more successful it was, the more further petitions that person ends up signing. However we also find that people who sign more typically have lower thresholds: they are willing to sign petitions which don't have very many signatures at the time they sign them.

The results from the Poisson regression are average effects. The logistic regressions (models B1 - B4) clarify which of these variables are important in terms of generating power users. The findings for models B1 - B2, which compare power users with different groups of low frequency users, are virtually identical. In terms of resources (H1.1) they show that, when low frequency users are compared to power users (the 100+ signature set), time appears to continue to play an important role: someone who signs more than 100 petitions is much more likely to be unemployed or retired than someone who signs only a few petitions. In terms of experiences (H1.2), the result of the first petition and the threshold of the user also have a similar effect. Model B3 continues to support most of these conclusions, though time is no longer statistically significant. By contrast, model B4, which compares the group who signed between 50 and 100 petitions with the group who signed more than 100 , offers different conclusions. The only statistically significant difference between these two groups is the threshold: individuals signing more than 100 petitions are likely to be willing to sign petitions with fewer signatures than 
individuals in the 50-100 signature group. This is intriguing and provides suggestive evidence that psychological traits, rather than either resources or experiences, may be the key factor in explaining power user emergence.

Taken together, these results allow us to offer a tentative summary of the differences between normal and power users. Normal, low frequency users (who have signed less than 50 petitions) are more likely to be employed, more likely to have had an unsuccessful first experience with the site, and more likely to have a high threshold for signing. Power users, by contrast (who signed more than 100 petitions), are frequently unemployed or retired, typically had a positive first experience, and typically have a low threshold for signing petitions. There is also a third middle category of users (who signed between 50 and 100 petitions): they are in many respects similar to the power users, distinguished only by having a higher threshold.

The fact that the impact of the first petition seems to be long lasting (but not permanent) points to a second line of investigation about learning. If people are stimulated to sign another petition by the results of the previous one, to what extent does that effect persist for subsequent petitions? We address this question in figure one. Each point in the figure represents the (exponentiated) coefficient from a simple logistic regression where the independent variable is the final number of signatures from petition $p_{i}$ and the dependent variable is whether the user signed petition $p_{i+1}$. As with table two, the average signature volume of petitions at the time of signing is included as a control variable. The y-axis represents how much the chance of signing the next petition is increased by the amount of signatures on the present petition. So, for example, the leftmost point on the graph indicates that, as signatures on the first petition a user signs increase by a factor of 10, the chance of signing a second petition increases by a factor of just over 1.25.

[figure one about here] 
Figure 1: Effect of result of petition $p_{i}$ on the chances of signing at least $p_{i+1}$ petitions. Ranges around points indicate $95 \%$ confidence intervals.

The image shows that the results of the first four petitions seem to have a positive impact on user behavior: individuals are more motivated to sign a subsequent petition if the previous one they signed received more signatures. However, after a user has signed five petitions, this impact diminishes: the chance of signing (say) the tenth petition is not influence by the results of the ninth. What this shows is that positive learning effects only seem to occur in the first few interactions with a site: after this point, users appear to cease being interested in signals about the potential efficacy of their actions.

We will now move on to addressing the impact of power users. We test two hypotheses in this section. First, we address H2.1, which concerns the topics in which different types of users are interested. We explore this question in figure two, which looks at the types of petition signed according to the amount of previous petitions signed by the user. The results of this graphic show a clear pattern of difference. First time signatures (the leftmost column) are distributed into quite a wide range of categories: politics, human rights, environment, arts and culture and social affairs all receive some representation. By contrast, those who sign the most petitions tend to focus almost exclusively on animal protection and animal rights. This shows that the interests of those who participate the most are quite different from casual users of the site, supporting H2.1.

[figure two about here]

Figure 2: Distribution of signatures by type of user

Finally, we will look at $\mathrm{H} 2.2$, which concerns the extent to which the petitions power users create are more successful than those created by the average user. This is tackled in table three, 
which presents two Poisson regressions seeking to explain the amount of signatures a petition receives (again, coefficients are exponentiated, and all numerical variables are standardized). Similar to the logic in table two above, the first model (C1) contains the number of signatures made by the creator of a given petition as a continuous independent variable. This allows us to look at average effects. In the second model (C2), this continuous variable is turned into a categorical one, to try and identify the particular impact of power users. Models C3 and C4 duplicate models $\mathrm{C} 1$ and $\mathrm{C} 2$, with the category of the petition included as a control variable, as we might expect the amount off signatures to be unequally distributed across categories.

[table three about here]

This model provides support for $\mathrm{H} 2.2$, by lending weight to the idea that people who have signed more petitions also end up creating more successful ones. This effect can be seen both in the models using the number of petitions signed by the creator as a continuous variable (models $\mathrm{C} 1$ and C3) and in the models which break the variable down into categories (models C2 and C4): even those who have signed 2-10 petitions create more successful petitions than those who sign only one. Intriguingly, however, we find that the size of effect seems to increase with the number of petitions signed, but only up until a certain point: those who signed 51-100 petitions are considerably more successful than those who sign more than 100. The addition of data on the topic of the petition in models $\mathrm{C} 3$ and $\mathrm{C} 4$ increases the $\mathrm{R}^{2}$ of the models considerably, though does not change the results. 


\section{Discussion}

In this paper, we have shown that power users have a significant impact on the lapetition.be site. Importantly, this was not just in terms of the overall volume of signatures, but also in terms of creating more successful petitions. This matters because, as we also demonstrated, the substantive interests of power users are quite different from normal users. Hence, we may have a very biased view of what people are interested in and concerned about if we focus on the petition topics where the majority of signatures take place, as they are likely to be generated by a minority of highly active users. This suggests that online democratic mechanisms need to take steps to promote the views of the majority of users who are less active, or at least limit the impact of the highly active. One example of this would be to only allow people to sign one petition per month (in the same way that people only vote periodically at election time). This would be especially crucial if major democratic institutions follow the example of the German Bundestag or of the British House of Commons: both institutions have institutionalized platforms of online petitioning that guarantee that petitions reaching a certain amount of signatures would automatically initiate either parliamentary debates or public hearings in parliament on the topic of the e-petition.

The disproportionate impact of power users also makes it even more vital to understand the reasons for their emergence. We showed that having more free time matters, with those without a job typically signing more. For example, even though unemployed people constituted a small absolute number of people who used the site (less than 10\%), they were the most active in terms of number of petitions signed (averaging more than five per person). Again, this seems significant: in one sense, it might allow unemployed individuals to redress some typical 
participation inequalities, by making use of the resources they have available (as highlighted in the literature review section, there is evidence that unemployed people are less likely to vote). However it also cuts against the notion that online participative activities are essentially cost free: even though the transactions take very little time to complete (and hence we might expect that time was not a factor), those who have more free time seem to participate much more. This suggests that there are other time-consuming elements to online democratic participation (such as the time cost of learning about issues).

We also moved beyond resource theory to investigate experiential components of participation. We demonstrated good support for the idea that power users are people who have low thresholds for participation, and who are willing to get things started. This is shown by the fact that they sign petitions which have few signatures, which may act as a way of getting things going. Furthermore, we demonstrated support for the idea that people learn from their initial experiences with a site, with people who signed a successful petition more likely to come back than those who signed a failing petition. These effects were surprisingly persistent: having an initial early success improved not just the chances of returning once, but the chances of coming back lots of times. However, the learning effect also declined quickly: the volume of signatures found on petitions which were fifth or later in the series of petitions users signed was no longer associated with any increased likelihood of signing more. This finding seems of particular significance for the design of democratic websites: they need to seek ways to give people initial successful interactions in order to encourage further use of such sites. 


\section{References}

Almond, G. A \& Verba, S. (1963). The Civic Culture: Political Attitudes and Democracy in Five Nations. London: SAGE Publications.

Arguello, J., Butler, B. \& Joyce, E. (2006). Talk to me: foundations for successful individualgroup interactions in online communities. Proceedings of the SIGCHI Conference on Human Factors in Computing Systems, 959-68.

Benewick, R, Birch, A., Blumler, J. \& Ewbank, A. (1969). The Floating Voter and the Liberal View of Representation. Political Studies, 17(2), 177-195.

Boldi, P., Bonchi, F., Castillo, C. \& Vigna, S. (2011). Viscous democracy for social networks. Communications of the ACM, 54(6), 129-137.

Brady, H., Verba, S. \& Schlozman, K. (1995). Beyond SES: A Resource Model of Political Participation. American Political Science Review, 89(2), 271-294.

Brandtzaeg, P. \& Heim, J. (2011). A typology of social networking sites users. International Journal of Web Based Communities, 7(1), 28-51.

Brandtzaeg, P. \& Heim, J. (2008). User loyalty and online communities: why members of online communities are not faithful. Proceedings of the 2nd International Conference on Intelligent Technologies for Interactive entertainment.

Bright, J. (2016). The Social News Gap: How News Reading and News Sharing Diverge. Journal of Communication, 66(3), 343-365.

Cantijoch, M., Cutts, D. \& Gibson, R. (2012). Internet use and political engagement: the role of e-campaigning as a pathway to online political participation." In International Political Science Association Xxii World Congress, 31.

Carman, C. (2014). Barriers are Barriers: Asymmetric Participation in the Scottish Public Petitions System. Parliamentary Affairs, 67(1), 151-71.

Cobo, C., Bulger, M., Bright, J. \& Rooijen, R. (2016). What Role Do 'Power Learners' Play in Online Learning Communities? In Proceedings of Linc, 7th Conference of the Learning International Networks Consortium, 83-92.

Contamin, J. (2012). Petitions. In: D. della Porta, B. Klandermans, and D. McAdam (Eds.), The Blackwell Encyclopedia of Social and Political Movements. London: Blackwell.

Cruickshank, P. \& Smith, C. (2011). Understanding 'the e-petitioner'. Transforming Government: People, Process and Policy 5(4), 319-329.

Edelmann, N. (2013). Reviewing the definitions of 'lurkers' and some implications for online research. Cyberpsychology, Behavior and Social Networking, 16(9), 645-649.

Finkel, S. \& Muller, E. (1998). Rational Choice and the Dynamics of Collective Political Action: Evaluating Alternative Models with Panel Data. American Political Science Review, 92(1), 37. 
Fisher, D., Smith, M. \& Welser, H. (2006). You Are Who You Talk To: Detecting Roles in Usenet Newsgroups. In Proceedings of the 39th Annual Hawaii International Conference on System Sciences, 59.

Gallego, A. (2007). Unequal Political Participation in Europe. International Journal of Sociology, 37(4), 10-25.

Goodin, R. \& Dryzek, J. (1980). Rational Participation: The Politics of Relative Power. British Journal of Political Science, 10(3), 273-92.

Granovetter, M. (1978). Threshold Models of Collective Behavior. American Journal of Sociology, 83(6), 1420-1443.

Hale, S., John, P., Margetts, H. \& Yasseri, T. (2014). Investigating Political Participation and Social Information Using Big Data and a Natural Experiment. APSA 2014 Annual Meeting.

Huang, S., Suh, M., Hill, B. \& Hsieh, G. (2015). How Activists Are Both Born and Made. In Proceedings of the 33rd Annual Acm Conference on Human Factors in Computing Systems, 211-220.

Karpf, D. (2011). Open Source Political Community Development: A Five-Stage Adoption Process. Journal of Information Technology \& Politics, 8(3), 323-345.

Kaye, B. \& Johnson, T. (2002). Online and in the Know: Uses and Gratifications of the Web for Political Information. Journal of Broadcasting \& Electronic Media, 46(1), 54-71.

Kitschelt, H. (1989). The Internal Politics of Parties: The Law of Curvilinear Disparity Revisited. Political Studies, 37(3), 400-421.

Kittilson, M. (2005). Changing Patterns of Mobilization, Increasing Bias?: Trends in Participation in Established Democracies, 1960-2003. Paper Presented at the Annual Meeting of the American Political Science Association.

Kittur, A, Chi, E., Pendleton, B, Suh, B. \& Mytkowicz, T. (2007). Power of the few vs. wisdom of the crowd: Wikipedia and the rise of the bourgeoisie. Algorithmica, 1(1), 9-2.

Lampe, C. \& Resnick, P. (2004). Slash(dot) and burn. In Proceedings of the 2004 Conference on Human Factors in Computing Systems, 543-550.

Lave, J. \& Wenger, E. (1991). Situated learning: Legitimate peripheral participation. Cambridge: Cambridge University Press.

Lijphart, A. (1997). Unequal Participation: Democracy’s Unresolved Dilemma. American Political Science Review, 91(1), 1-14.

Lindner, R. \& Riehm, U. (2009). Electronic petitions and institutional modernization. JeDEM eJournal of eDemocracy and Open Government, 1(1), 1-11. 
Lupia, A. \& Sin, G. (2003). Which Public Goods are Endangered? How Evolving Communication Technologies Affect The Logic of Collective Action. Public Choice, $117(3 / 4), 315-331$.

Margetts, H., John, P., Hale S. \& Reissfelder, S. (2015). Leadership without leaders? Starters and followers in online collective action. Political Studies, 63(2), 278-299.

Margetts, H., John, P., Hale, S. \& Yasseri, T. (2015). Political Turbulence: How Social Media Shape Collective Action. Princeton: Princeton University Press.

May, J. (1972). Opinion Structure of Political Parties: The Special Law of Curvilinear Disparity. Political Studies, 21(2), 135-151.

Morozov, E. (2011). The Net Delusion. London: Penguin

Muller, M. (2012). Lurking as personal trait or situational disposition. Proceedings of the Acm 2012 Conference on Computer Supported Cooperative Work.

Nie, N. \& Verba, S. (1975). Political Participation. Handbook of Political Science, Vol. 4, 1-74.

Nielsen, J. (2006). Participation Inequality: The 90-9-1 Rule for Social Features. Available from: http://www.nngroup.com/articles/participation-inequality/

Norris, P. (1995). May's Law of Curvilinear Disparity Revisited: Leaders, Officers, Members and Voters in British Political Parties. Party Politics, 1(1), 29-47.

Oser, J., Leighley, J. \& Winneg, K. (2014). Participation, Online and Otherwise: What's the Difference for Policy Preferences? Social Science Quarterly, 95(5), 1259-1277.

Pal, A., Farzan, R., Konstan, J. \& Kraut, R. (2011). Early detection of potential experts in question answering communities. UMAP'11 Proceedings of the 19th International Conference on User Modeling, Adaption, and Personalization, 231-242.

Panciera, K., Halfaker, A. \& Terveen, L. (2009). Wikipedians are born, not made: a study of power editors on Wikipedia. In Proceedings of the 2009 International Conference on Supporting Group Work, 51-60.

Panciera, K., Priedhorsky, R., Erickson, T. \& Terveen, L. (2010). Lurking? Cyclopaths? A Quantitative Lifecycle Analysis of User Behavior in a Geowiki. In Proceedings of the 28th International Conference on Human Factors in Computing Systems, 1917-1926.

Parry, G. (1992). Political Participation and Democracy in Britain. Oxford: Oxford University Press.

Preece, J. \& Shneiderman, B. (2009). The reader-to-leader framework: Motivating technologymediated social participation. AIS Transactions on Human-Computer Interaction, 1(1), $13-32$.

Priedhorsky, R., Chen, J., Lam, S., Panciera, K., Terveen, L. \& Riedl, J. (2007). Creating, destroying, and restoring value in wikipedia. In Proceedings of the 2007 International Acm Conference on Conference on Supporting Group Work, 259. 
Puschmann, C., Bastos, M. T., \& Schmidt, J.-H. (2017). Birds of a feather petition together? Characterizing e-petitioning through the lens of platform data. Information, Communication \& Society, 20(2), 203-220.

Sauermann, H. \& Franzoni, C. (2015). Crowd science user contribution patterns and their implications. PNAS, 112(3), 679-684.

Schlozman, K., Burns, N. \& Verba, S. (1999). "What Happened at Work Today?": A Multistage Model of Gender, Employment, and Political Participation. Journal of Politics, 61(1), 2953.

Schlozman, K., Verba, S. \& Brady, H. (2010). Weapon of the Strong? Participatory Inequality and the Internet. Perspectives on Politics, 8(2), 487-509.

Schmidt, J. \& Johnsen, K. (2014). On the Use of the E-Petition Platform of the German Bundestag. SSRN Electronic Journal.

Schroer, J. \& Hertel, G. (2009). Voluntary Engagement in an Open Web-Based Encyclopedia: Wikipedians and Why They Do It. Media Psychology, 12(1), 96-120.

Scott, W. \& Acock, A. (1979). Socioeconomic status, unemployment experience, and political participation: A disentangling of main and interaction effects. Political Behavior, 1(4), 361-381.

Shulman, S. (2009). The Case Against Mass E-mails: Perverse Incentives and Low Quality Public Participation in U.S. Federal Rulemaking. Policy \& Internet, 1(1), 22-52.

Sun, N., Rau, P. \& Ma, L. (2014). Understanding lurkers in online communities: A literature review. Computers in Human Behavior, 38, 110-117.

Utych, S. \& Kam, C. (2014). Viability, Information Seeking, and Vote Choice. Journal of Politics, 76(1), 152-166.

Vaccari, C. (2013). Digital Politics in Western Democracies. Bologna: Johns Hopkins Press.

Whittaker, S., Terveen, L., Hill, W., Cherny, L., Ave, P. \& Park, F. (1988). The dynamics of mass interaction. Proceedings of the ACM Conference on Computer-Supported Cooperative Work, 257-264.

Wilson, J. (2000). Volunteering. Annual Review of Sociology, 26(1), 215-240.

Yasseri, T. Bright, J. (2016). Wikipedia traffic data and electoral prediction: towards theoretically informed models. EPJ Data Science, 5(22).

Yasseri, Taha, Scott A. Hale, and Helen Margetts. 2013. "Modeling the rise in Internet-based petitions." Available from: http://arxiv.org/abs/1308.0239.

Yeow, A., Johnson, S. \& Faraj, S. (2006). Lurking: Legitimate or Illegitimate Peripheral Participation? Proceedings of the 27th International Conference on Information Systems, 967-82. 